\title{
El concepto Realpolitik en la ciencia política
}

DOI: https://doi.org/10.32870/

eees.v26i76.7023

Ignacio Medina-Núñez*

Desde la Antigüedad, remontándonos a los pensadores griegos clásicos, podemos encontrar cierta distinción que se ha hecho entre el concepto de la política como un ideal de acción colectiva de los ciudadanos para impulsar el bien común de una comunidad y la manera real en que se hace la política en situaciones determinadas. Platón, por ejemplo, puede situarse en una corriente idealista (sobre todo en La República), que contrasta con la visión más realista de Aristóteles en su Política, donde este filósofo realiza su análisis sobre las numerosas constituciones de las ciudades-Estado de Grecia y reflexiona sobre las diversas formas de Gobierno como la monarquía, la aristocracia y la democracia.

Esta distinción tradicional entre idealismo y realismo de la política recibió un giro particular en el siglo Xvi en Europa, cuando se empezó a imponer la visión de Maquiavelo, particularmente tras su estudio El Príncipe, publicado en 1532, según el cual la política debía ser entendida sobre todo como una lucha descarnada por el poder en que se pueden usar todos los medios para conquistarlo

-ProfesorInvestigador de El Colegio de Jalisco, México. ORCID: https:// orcid.org/0000-00021660-2327 medina48 @yahoo.com o conservarlo. No obstante, la visión idealista de la política nunca ha desapa-

John Bew (2016). Realpolitik. A history. Nueva York: Oxford University Press. 
recido por completo: en el mismo siglo XVI, Tomás Moro escribió su libro Utopía, que imaginaba una sociedad con funcionamiento político ideal. Más aún, la corriente idealista se acrecentó en la época moderna, de lo que es ejemplo la Historia de la utopía planetaria, de Armand Mattelart.

Cuando John Bew, en el libro aquí reseñado, habla del nacimiento del concepto de la Realpolitik, en el siglo XIX, señala cómo este término ha sido asociado con cierto redescubrimiento de los escritos de Maquiavelo en la época contemporánea, a la que ciertos autores, como Michael Ignatieff, se han referido como otro momento de Maquiavelo.

No obstante, lo que hace Bew en este libro es un análisis más complejo del concepto en cuestión, por lo que permiteir más allá de un retorno a la corriente realista del pensamiento sobre política -corriente que muchas veces ha sido aplicada solamente al marco de las relaciones internacionales-.

El libro de Bew permite identificar que aunque Maquiavelo podría ser el padre de la Realpolitik se reconoce que este concepto -incluso lo vemos en la conservación de la palabra original alemana- apareció en el siglo XIx en Alemania, particularmente cuando el periodista y activista liberal August Ludwig von Rochau escribió su libro Foundations of Realpolitik (Grundsätze der Realpolitik), en 1853, y al cual le añadiría después un segundo volumen, publicado en 1869.

En estos libros fundacionales del concepto podemos encontrar su significado original:

El concepto de Realpolitik fue un intento de responder a los retos y adivinanzas de la política doméstica: cómo construir un Estado nación liberal y estable en un frágil y rápidamente cambiante entorno, sin recurrir a la convulsión y la represión [...]. Para tener éxito, el hombre de Estado debía entender las circunstancias históricas en que estaba operando y las condiciones de la modernidad en una era de un rápido desarrollo económico, político e intelectual. (pp. 17-18) 
En ese sentido, el concepto estaría necesariamente vinculado al contexto de las revoluciones sucedientes en numerosos países europeos en 1848, en las que se habían insertado con fuerza los movimientos socialistas, comunistas y liberales, pero que también terminaron en fracaso por la represión gubernamental o por la descoordinación y errores de sus dirigentes.

Fue en dicho contexto de falsas esperanzas y ambiciones frustradas que Von Rochau introdujo el concepto. A mediados del siglo XIx, Von Rochau era un liberal alemán, aunque de joven había tenido posiciones políticas más radicales. El contexto de las revoluciones del 1848 lo había sumergido en una crisis ideológica: por un lado, se tenía que aceptar el fracaso de ciertos ideales propuestos por el socialismo utópico de Charles Fourier y Saint-Simon, y por otro, estaba la opción de aceptar el mundo tal cual era sin la posibilidad de posibles cambios para mejorar la sociedad. Mientras que el idealismo y los utopistas podrían representar la opción de construir castillos en el aire, en el lado opuesto estaba la opción de adaptarse al mundo real, tal como es.

Por otro lado, en aquel tiempo, se podía considerar también la influencia del naciente marxismo a través de escritos como el Manifiesto comunista, de 1848, o el 18 Brumario de Luis Bonaparte, publicado en 1852. Las palabras de Marx podrían haber sido una propuesta intermedia, al señalar que los hombres hacen su historia según sus circunstancias. Como dice John Bew, "Ludwig von Rochau jamás mencionó a Marx directamente, aunque le pidió prestadas numerosas frases. Esta versión del argumento marxista fue otro de los preceptos fundamentales de la Realpolitik" (p. 27).

También, comúnmente se ha asociado este concepto a políticos como Metternich o Bismarck, aunque ellos nunca lo utilizaron. Así, hay que insistir en que fue Von Rochau su inventor, aunque sus propuestas teóricas fueron eclécticas y algo confusas. Para poder aprehenderlo, queda en la his-

Reseñas No.76 
toria su texto original de 1853, publicado luego en segunda edición en 1859 con algunos comentarios adicionales. El segundo volumen, como ya se dijo, de 1869, replicaría a algunas críticas recibidas sobre los Fundamentos.

El pensamiento de Von Rochau sobre la Realpolitik se desglosa en el primer libro en dos partes divididas en veintiún capítulos. La primera parte habla de la estructura del Estado y de las fuerzas sociales en su interior; la segunda parte trata de aplicar su teoría hacia las circunstancias particulares de Alemania en ese tiempo.

Se podrían señalar cuatro aspectos fundamentales sobre su propuesta: 1) la ley del más fuerte es un factor determinante en la política; 2) la forma más efectiva de un Gobierno es aquella que incorpora a las más poderosas fuerzas sociales dentro del Estado, fortalece sus energías y logra un balance entre ellas; 3) en política, las ideas importan mucho, pero el papel que juegan ha sido malinterpretado porque ideas inmorales o incultas han sido más poderosas que las nobles según la gente se ha aferrado a ellas y las ha conservado con fortaleza; y 4) la modernidad ha cambiado la naturaleza del poder del Estado, con la opinión pública actuando de forma más importante que el Zeitgeist (espíritu de una época) para determinar la trayectoria política de una nación.

En ese sentido, el primer capítulo del libro de Bew aquí reseñado nos lleva precisamente al origen del concepto, a partir tanto de su creador original como del contexto específico del Gobierno de Bismarck y de la etapa inmediatamente posterior a Von Rochau. La vinculación del pensamiento de Bismarck en la construcción de la Alemania unificada con la concepción de la Realpolitik queda manifiesta en su posición expresada en un discurso de 1862: "Los problemas más importantes de nuestro tiempo no serán decididos a través de discursos o por decisiones mayoritarias -ese fue el error de 1848-9- sino con sangre y hierro" (p. 47). 
El proyecto de la unificación de Alemania de Bismarck habría atraído incluso a la corriente liberal, que, en la perspectiva de Von Rochau, reconocía el liderazgo de Bismarck sin renunciar a sus propósitos de libertad y sufragio universal:

Los liberales alemanes han tenido que aceptar el hecho de que Bismarck ha tomado la iniciativa en la cuestión nacional de Alemania. Ahora ellos están preparados para negociar con él en estos asuntos. Pero ello no conlleva la renuncia al juicio individual ni requiere la sumisión acrítica al poder tal como está. (p. 54)

La discusión fundamental que Von Rochau propuso de manera explícita se puede encontrar en el libro de 1869, en el capítulo quinto, "Idealismo político y realidad". En él, la Realpolitik se convierte en una propuesta que no renuncia a las metas ideales, pero asume que se hace necesario analizar con detenimiento las circunstancias históricas para saber con precisión qué es posible construir en el presente.

Von Rochau murió en Heidelberg en 1873. Después, su nombre ha sido olvidado, aunque el concepto Realpolitik ha tomado vida propia. En ese sentido, John Bew termina la primera parte de su libro señalando que se empezaron a desarrollar aplicaciones de este concepto con otras interpretaciones, una de ellas en el escenario internacional mediante el concepto de Weltpolitik, esto en la última década del siglo XIX.

A continuación, se señalan de manera sintética algunas consideraciones que nos ayudarían a tener una visión completa de la obra aquí reseñada.

La parte dos del libro, "La anti-Realpolitik y la visión anglo-americana", describe cómo el concepto llegó a Inglaterra y a Estados Unidos con una gran variedad de significados, que se fueron ampliando desde finales del siglo XIX hasta la Primera Guerra Mundial. Para entonces, muy

Reseñas No.76 
pocos recordaban a Von Rochau porque el concepto se ligó al militarismo prusiano y del imperialismo alemán. Las palabras Realpolitik, Weltpolitik o Machtpolitik no eran más que una expresión peyorativa vinculada a la política del uso de la fuerza propia de Alemania. De esta manera, lo que empezó a prevalecer en Inglaterra y Estados Unidos fue una visión de la anti-Realpolitik, lo que hacía referencia a la necesidad de un antídoto frente a la política militarista que existía en el sistema internacional en su conjunto.

El libro de Bew también detalla cómo fue la primera vez que fue usado el concepto de Realpolitik en una publicación inglesa, en el London Illustrated Review de 1872. Después, refiere la segunda ocasión en que fue citado el concepto, en 1895, tras la dimisión de Bismarck, cuando se calificaba a la Realpolitk como un realismo de hecho dentro del moderno imperio alemán que habría tenido un corrosivo efecto en aquella nación de pensadores.

Bew también señala que otro autor inglés comenzó a referir este concepto en 1902 como sinónimo de una enfermedad dentro de las relaciones internacionales. Así, para Inglaterra, el significado de la Realpolitik solamente se vinculaba a un descarado maquiavelismo de Alemania y de otros poderes continentales.

En los Estados Unidos, de 1900 a 1914, la palabra Realpolitik "nunca adquirió las negativas connotaciones que había adquirido en Europa" (p. 107). Bew señala que el periodista Walter Weyl fue el primero que introdujo el término, pero que fue Walter Lippman quien lo popularizó, aunque escribiéndolo en minúsculas y sin cursivas: "realpolitik", esta vez con un significado muy parecido al de geopolítica; fue también el momento en que Estados Unidos "se estableció a sí mismo como un rival serio frente a otros superpoderes en el escenario internacional" (p. 108).

Se estaba formando el contexto del siglo xx con una nueva visión, en donde Estados Unidos entendió el nuevo rol 
que podía tener en las relaciones internacionales con una ideología liberal, como el presidente Wilson lo anunció en enero de 1918, según es retomado por Bew: "una política de libre comercio, negociación con las otras naciones y una democracia y autodeterminación como los principios organizadores de las relaciones internacionales" (p. 130). Así, el nuevo significado se expresaba en un internacionalismo liberal en contra de los regímenes de poder y de fuerza.

La parte tres del libro de Bew se titula "Una Realpolitik entre guerras". Bew detalla cómo el contexto internacional cambia con el fin de la Primera Guerra Mundial, los acuerdos entre Estados Unidos e Inglaterra para su mutua convivencia como potencias mundiales y, sobre todo, la emergencia de la Unión Soviética tras la Revolución rusa, en 1917. Bew analiza al gran pensador que fue Max Weber respecto de su concepción de la Realpolitik en su obra $L a$ política como vocación.

Bew señala que en los Estados Unidos se combinaban la idea de mantener una paz mediante la concertación en un mundo tan complejo y el esfuerzo de hacer prevalecer los intereses norteamericanos por la fuerza. Bew recuerda que sobre el presidente norteamericano Herbert Hoover alguien pudo decir que "le preocupa más la eficiencia que el idealismo académico" (p. 149). Estas preocupaciones de los estadounidenses se explicaban, además, porque "a pesar de la derrota de 1918, Alemania no quería dejar atrás totalmente la Realpolitik" (p. 162).

Para la década de 1920, la Liga de las Naciones como ideal humanitario de un Gobierno mundial era casi un cuerpo muerto. Apareció entonces otro momento maquiavélico con el surgimiento del fascismo y sus terribles consecuencias, evidenciadas como nunca en la Segunda Guerra Mundial. Es lógico que en la posguerra volviera a aparecer con énfasis la anti-Realpolitik que había promulgado Inglaterra, aunque como dijo también un político inglés en 1945: "el hecho de 
que nosotros somos realistas, no nos impide también el ser idealistas" (p. 182). Esto último refleja los vaivenes de la categoría principal que analiza el libro de Bew, envuelta no sólo en discusiones académicas sino también en el enredo de la política internacional.

La parte cuatro del libro, "La Realpolitik y las raíces enredadas del realismo norteamericano", centra la discusión de Bew en la Guerra Fría, tras la victoria de los aliados contra la Alemania de Hitler, pero específicamente en el debate académico en Norteamérica, en donde tuvieron predominancia las universidades de Chicago y Yale. Era el retorno de la geopolítica en un nuevo contexto donde Estados Unidos se había convertido en una superpotencia, aunque enfrentada en las relaciones internacionales al poderío de la Unión Soviética.

Ahora bien, el pensamiento norteamericano de la época también estuvo influenciado por numerosos migrantes alemanes que llegaron a territorio norteamericano, uno de ellos el jurista y teórico de las relaciones internacionales Hans Joachim Morgenthau (1904-1980), quien generó una gran tradición en la concepción de la "realpolitik": había sido idealista y optimista en su juventud respecto al potencial de la ley internacional como un instrumento para la resolución de conflictos, pero acabó creyendo que el escenario internacional era una arena con "peleas interminables por la sobrevivencia y el poder" (p. 209).

Con ello, se había convertido en el último exponente del realismo anglo-americano, como se expresa en su libro de 1948, Politics among Nations, con una frase contundente (que se toma del libro de Bew): "El realismo mantiene que los principios morales universales no pueden ser aplicados a la acción de los Estados" (p. 209).

Bew recuerda que Morgenthau había señalado cuatro grandes males que debían ser afrontados por la política exterior norteamericana: el utopismo, el sentimentalismo, 
el legalismo y el nuevo aislacionismo, pero también que esta misma posición de Morgenthau fue confrontada dentro de Estados Unidos, donde se le señaló como un seguidor de Maquiavelo que retornaba a la Realpolitik como confianza única en el poder real que se tiene.

Por otro lado, Bew resalta también la nueva aparición de la figura de Bismarck en Estados Unidos en un debate que atribuía a la Realpolitik de dicho gobernante la causa de la unificación de Alemania en el siglo XIx. Toda esta discusión sobre el concepto se alejaría bastante de los orígenes, puesto que ya nadie haría mención alguna de Von Rochau.

La última parte del libro de Bew se titula "La Realpolitik práctica", y cuenta a su vez con tres apartados enfocados en la tercera parte del siglo xx: "La Realpolitik ante la distensión mundial", "El efecto Kissinger" ("porque el acercamiento a los asuntos de la política exterior por parte de Kissinger-Nixon llegó a convertirse en un sinónimo de la realpolitik" -p. 241-, aunque la administración de Carter se distanció del término), y "De la Guerra Fría al nuevo orden mundial".

Según narra Bew, el término siguió discutiéndose entre teóricos académicos y teóricos específicamente del área de relaciones internacionales, y fue utilizado frecuentemente en Estados Unidos en el ámbito diplomático por el Departamento de Estado y la Agencia Central de Inteligencia (CIA, por sus siglas en inglés). También continuó siendo polémico: para algunos mantuvo su carácter peyorativo, mientras que para otros se consolidó como algo positivo frente a la ingenuidad del idealismo; para algunos era símbolo de cinismo y pesimismo, mientras que para otros lo era de madurez. El autor finalmente presenta los diversos usos de la "realpolitik" en las etapas últimas de la Guerra Fría, y señala que después de la caída del Muro de Berlín el concepto estuvo en desuso, aunque ha vuelto a aparecer en el siglo XXI.

El libro termina con una conclusión titulada "Retorno a los fundamentos". Bew realiza ahí una serie de considera- 
ciones muy importantes para la ciencia política. Señala en primer lugar que hay que enfatizar la importancia de la historia al exponer las circunstancias de cualquier situación política: "se trata de un intento de anticipar y de poder construir el futuro" (p. 299). Por ello, reconoce el origen del concepto en Ludwig von Rochau, quien ofrecía "una simple pero sencilla fórmula para acercarse mejor a los dilemas de la política exterior" (p. 300), además con el elemento básico de mirar el mundo real para evitar ciertos tipos de idealismo que solamente construyen, de nuevo, castillos en el aire.

Uno de los elementos básicos del concepto es la posibilidad de considerar siempre lo que es posible conseguir en un momento determinado sin dejar de darle importancia al idealismo y la utopía, fuerzas de cambio y transformación. El concepto se puede convertir en un instrumento adecuado para analizar el mundo complejo de las ideas, el poder y la sociedad en su conjunto, a partir de un acercamiento al historicismo y el empirismo: llegar a saber el origen histórico de una situación determinada, entenderla y aceptarla en la forma en que ha llegado hasta nosotros para a su vez entender y construir las alternativas de un cambio posible. No se trata del culto maquiavélico al interés nacional bajo la figura de un mundo real de poder al cual hay que adaptarse, pero tampoco se debe dar lugar a la tradición anti-realpolitik que también ha prevalecido en diversos momentos en la política exterior anglo-americana.

Finalmente, recomendamos la lectura del libro aquí reseñado porque explica esta categoría como un instrumento muy positivo de análisis para la ciencia política contemporánea. 